Clinical Anatomy 15:70 (2002)

\title{
OBITUARY
}

\section{Russell Thomas Woodburne}

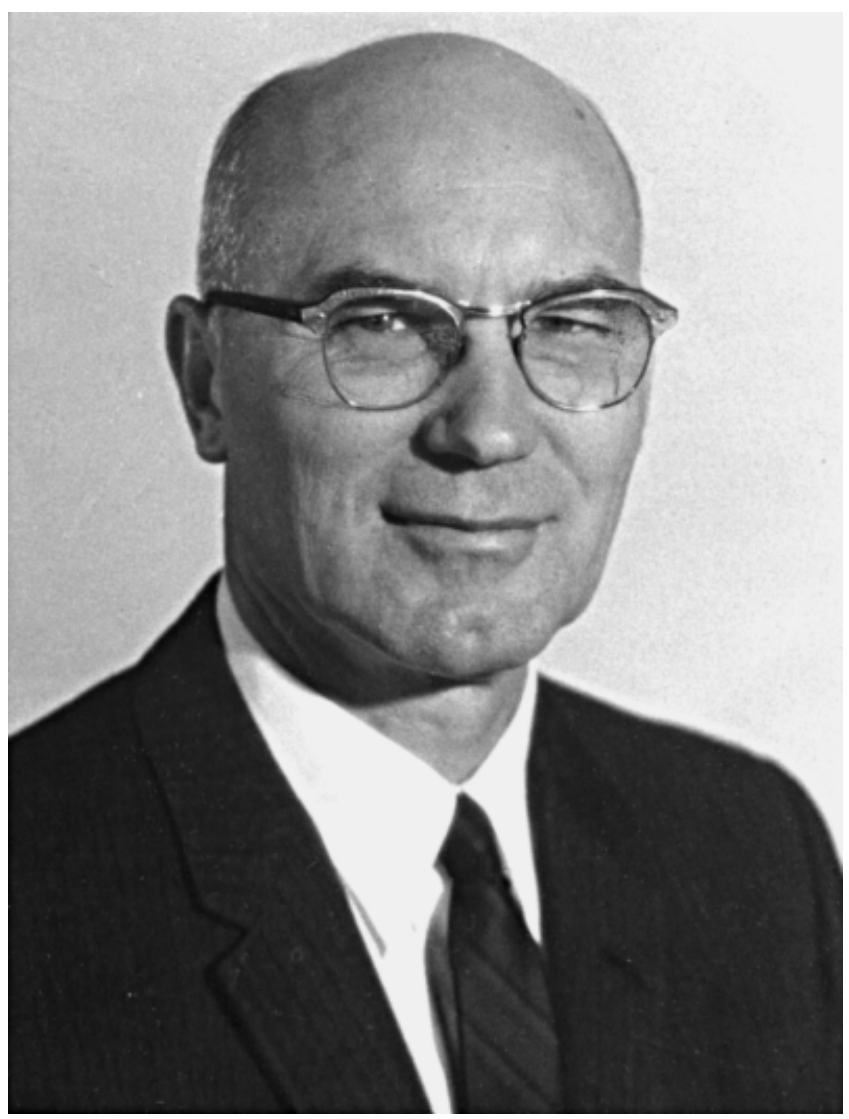

Russell Thomas Woodburne, MA, PhD passed away on April 11, 2001 after a short illness. Russ was a spry 96 year-old at his death. He is survived by his wife of 66 years, Betty and three children, Mike, Jean and Susan. He was Professor Emeritus of Anatomy at the University of Michigan and the former Chairman of the Department. Russ was Canadian by birth, born in London, Ontario on November 2,1904 . He emigrated with his family to the US in 1914 . He spent his entire academic career at the University of Michigan, starting as an undergraduate in 1928, receiving a BA in '32, MA in Psychology in '33 and a PhD in Anatomy in '34 under G. Carl Huber. He spent his early research years in study of the comparative anatomy of the mammalian midbrain working with the renowned neuroanatomists G. Carl Huber and Elizabeth C. Crosby with whom he published several papers. In the 1950's his interest turned from neuro to gross anatomy, culminating in the publication of the first edition of Essentials of Human Anatomy (Oxford University Press) in 1958. Although preceded by Grants Method of Anatomy by several years, it was one of the first regionally organized anatomy texts and rivaled Gray's Anatomy for the completeness of its gross anatomical descriptions.

As his teaching interests turned to gross anatomy in his mid career, so did his research and he published several papers, both descriptive and applied, on various topics such as the pleura, aorta, pancreas, liver and especially the ureter and urinary bladder.

He was a gifted and enthusiastic teacher who introduced thousands of medical students to human anatomy during his long and productive career. He was known as an excellent lecturer and quite an artist with chalk. With the publication of Essentials, however, his lectures decreased, for as he said, "Why should I lecture on it? It's all in the text" (meaning the Essentials of Human Anatomy). Of course in those days courses in gross anatomy averaged well over 300 hours and students were expected to read the text. The general rule was that anything in the text was fair game for exams and an exam question might read "Describe the pancreas."

He was active in the American Association of Anatomists. He was on the Executive Committee ('55-59), Secretary-Treasurer ('64-'71) and President in '74-'75. He was member of several other associations and an honorary member of the Coller Surgical Society. The American Association of Clinical Anatomists chose him as their Honored Member of in 1987. He had a special interest in Anatomical Terminology and was a member of the Splanchnology Committee of the International Anatomical Nomeclature Committee ('60-'85) and chairman ('85-'90).

Russ resigned as chairman of Anatomy at Michigan in 1974 at the age of 70 to turn his attention to one of his great avocations-golf. He and his wife Betty were both excellent golfers and they continued to play until Russ was over ninety. In his later years, after he retired, he would come in to the office on Thursday mornings and we would work on the Essentials. Promptly at 10:00 we would stop for tea, one teabag for two cups and a saccharin tablet in each cup. Then we would get down to talking about important things, family, friends, golf, etc. and that's how I remember him, a friend and mentor, a teacher and a man of uncompromising integrity. We shall miss him.

\author{
William E. Burkel, PhD \\ Professor of Anatomical Sciences \\ The University of Michigan Medical School
}

